\title{
Prática médica homeopática e a integralidade
}

Carolina Santanna ${ }^{1}$

Élida Azevedo Hennington ${ }^{2}$ José Roque Junges ${ }^{3}$

SANTANNA, C.; HENNINGTON, E.A.; JUNGES, J.R. Homeopathic care and the principle of integrality. Interface - Comunic., Saúde, Educ., v.12, n.25, p.233-46, abr./jun. 2008.

The "Centro de Saúde Modelo" was the first Basic Health Care Service of the Brazilian Public Health System to introduce homeopathic care in the State of RS. The aim of this study was to understand this health center's contribution to the development of the integrality principle. This is a case study. The categories employed in guidying the study were: welcoming, bond and care. The data was based on documents, direct observation and interviews with professionals and people using the service. The results indicate that homeopathy, by welcoming and caring for each individual in his/her singularity and totality, makes a differentiated kind of assistance possible. However, integrality has been restricted to some aspects directly associated with the physician-patient relation such as bonding and care. The main problem identified was access to care. Homeopathy is coherent with and strengthens the principles of the Brazilian Public Health System and therefore it should be valued and become more widespread as a therapeutic option, thus contributing towards effectively achieving the goal of integral health care.

Key words: Integrality. Homeopathy. Health management. Case study.
O Centro de Saúde Modelo foi a primeira unidade do Sistema Único de Saúde (SUS) a implantar o serviço de atendimento homeopático no Rio Grande do Sul. Este estudo teve por objetivo conhecer a contribuição desse atendimento para o desenvolvimento do princípio da integralidade. Trata-se de estudo de caso utilizando, como categorias norteadoras, o acolhimento, o vínculo e o cuidado, sendo os dados produzidos com base em documentação, observação direta e entrevistas com usuários e trabalhadores. Os resultados indicam que a homeopatia, ao acolher e tratar pessoas em sua singularidade e totalidade, permite uma atenção diferenciada. Entretanto, a integralidade tem sido restrita a alguns de seus aspectos, como o vínculo e o cuidado diretamente associados à relação médico-usuário. A dificuldade de acesso foi o principal problema identificado. Coerente e fortalecedora dos princípios do SUS, a homeopatia deve ser valorizada como opção terapêutica para que possa efetivamente contribuir na integralidade da atenção em saúde.

Palavras-chave: Integralidade. Homeopatia. Gestão em saúde. Estudo de caso.

\footnotetext{
* Elaborado com base em Santanna, 2005.

${ }^{1}$ Relações Públicas. Secretária Municipal de Saúde, Prefeitura de Tapes. Rua Paul Harris, 277 - Tapes, RS 96.760-000 carolina.santanna@ yahoo.com.br

${ }_{2}^{2}$ Médica sanitarista. Instituto de Pesquisa Clínica Evandro Chagas, Escola Nacional de Saúde Pública, Fundação Oswaldo Cruz.

${ }^{3}$ Graduado em Filosofia e História. Programa de Pós-Graduação em Saúde Coletiva, Universidade do Vale do Rio dos Sinos.
} 


\section{Introdução}

A atenção aos usuários do sistema de saúde no Brasil ainda privilegia as especialidades médicas voltadas para as dimensões exclusivamente biológicas, em detrimento de uma abordagem que considere as dimensões psicossociais, éticas, culturais, econômicas e até políticas, reforçando a manutenção de uma prática fragmentária e reducionista por parte da equipe de saúde, especialmente dos médicos.

A crise paradigmática da biomedicina, representada pela sua excessiva tecnificação, especialização e custos crescentes, e por responder cada vez menos à demanda social concreta por saúde e cuidados médicos, evidencia-se, sobretudo, quando se trata de enfermidade cujo enfrentamento exige intervenções que integrem também a dinâmica da subjetividade, por estarem relacionadas a crises existenciais, conflitos diversos de naturezas psíquica, econômica e social que não podem mais ser enquadrados pelo método anátomo-clínico dominante (Guedes et al., 2006; Martins, 2003).

Esta crise deve ser considerada de fundamental importância no crescente aumento de interesse por outras racionalidades médicas. A partir da década de 1970 algumas dessas "novas racionalidades" chegaram ao Brasil e outras ganharam reconhecimento, acompanhando o movimento denominado Contracultura nos EUA, bem como outros movimentos sociais surgidos no pós-Segunda Guerra, na Europa, e também influenciadas por um novo sincretismo religioso mundial composto de diversas tradições orientais e ocidentais, mesmo que marcado pela tradição cristã (Martins, 2003; Luz, 1996a). As práticas terapêuticas consideradas "alternativas" ou "complementares" são, especialmente, aquelas centradas no paradigma vitalista ou paradigma de saúde, como a homeopatia (Luz, 1996b).

A homeopatia, reconhecida como especialidade pela Associação Médica Brasileira em 1979, vem sendo gradativamente incluída nos serviços públicos de saúde. Mesmo que ainda minoritária, hoje é uma importante opção de atendimento nos grandes centros urbanos do país. Ao definir a saúde como equilíbrio do princípio ou força vital, a homeopatia trabalha com a concepção positiva de saúde e tem sua abordagem voltada para estimular a autonomia dos sujeitos (Luz, 1988). Para Hahnemann (2001), quando qualquer agente hostil à vida, externo ou interno, atinge o indivíduo, este princípio de harmonia é influenciado pelo dinamismo do agente hostil, e é neste caso que a energia vital se altera, mudando seu ponto de equilíbrio, produzindo no organismo sensações desagradáveis e processos de adoecimento. Neste sentido, para o homeopata, restabelecer a saúde é restabelecer a harmonia no dinamismo da vida por meio da eliminação do conjunto de sintomas como um todo.

Esta concepção vem ao encontro do discurso atual da Saúde Pública direcionado para a promoção da saúde e que abre espaço para legitimar formas de conhecimento, além do modelo biomédico, buscando integrar outras racionalidades médicas (Carvalho, 1996). De acordo com as conclusões do $1^{\circ}$ Fórum Nacional de Homeopatia ocorrido em 2004, a homeopatia fortalece os princípios do SUS, pois, alicerçada no controle social, a mesma destina-se a consolidar, como parâmetro de qualidade de sua prática: a integralidade - compreendendo o sujeito enquanto unidade indivisível, que não deve ser submetido a limitações de recortes patológicos; a eqüidade-dimensionando a atenção às necessidades de saúde da população, respeitando as diferenças individuais, e, por fim, a universalidade - na garantia democrática do acesso a essa racionalidade enquanto direito de exercício de cidadania (Comissão de Saúde Pública, 2004).

Para Pinheiro e Luz (2003, p.65), a integralidade em saúde, no sentido ampliado de sua definição legal, deve ser entendida como "uma ação social que resulta da interação democrática entre atores no cotidiano de suas práticas na oferta do cuidado de saúde, nos diferentes níveis de atenção do sistema de saúde". Segundo Mattos (2001), existem, pelo menos, três sentidos para o termo integralidade no contexto da reforma sanitária brasileira. O primeiro se refere a atributos das práticas; o segundo sentido está relacionado aos aspectos da organização dos serviços, e o terceiro voltado para características de políticas ou de respostas governamentais a certos problemas de saúde. Segundo o mesmo autor, os beneficiários das ações de saúde têm sempre um conjunto muito grande de necessidades em relação ao serviço e uma das características das práticas de saúde pautadas na integralidade seria a escuta ampliada das necessidades de qualquer sujeito (Mattos, 2003). 
Este estudo teve por objetivo conhecer o atendimento homeopático prestado pelo Centro de Saúde Modelo, primeira unidade a implantar oficialmente o serviço de atendimento homeopático no Estado do Rio Grande do Sul, e sua contribuição para o desenvolvimento do princípio da integralidade na atenção à saúde.

\section{O percurso metodológico}

Esta pesquisa se caracterizou por ser um estudo de caso único qualitativo, realizado por meio da análise aprofundada de uma única unidade, neste caso, a prática médica homeopática no Centro de Saúde Modelo, na cidade de Porto Alegre (Yin, 2001; Triviños, 1987). A pesquisa foi realizada nessa unidade por ser o primeiro centro de saúde do SUS a implantar oficialmente o serviço de homeopatia no $\mathrm{RS}$, considerado, até hoje, referência neste tipo de atendimento para o município, região metropolitana e para outras cidades do estado.

Os dados foram produzidos com base em documentos, observação direta e na realização de entrevistas. As entrevistas foram semi-estruturadas, combinando perguntas abertas e fechadas, sendo que as fechadas foram utilizadas para a coleta de dados de identificação e caracterização demográfica e socioeconômica. A população deste estudo foi composta por todos os trabalhadores do serviço de atendimento homeopático, usuários e o gestor da unidade. Foi feito um total de dez entrevistas: cinco com trabalhadores de saúde (duas médicas, uma farmacêutica, duas auxiliares de saúde, identificadas nas falas com a numeração de 1 a 5), quatro com usuários do serviço (identificados nas falas com a numeração de 6 a 9), e com o gestor geral da unidade (entrevistado 10). Para a etapa das entrevistas com usuários, foram selecionados aqueles com, no mínimo, três consultas efetuadas no setor, com faixas etárias e perfis profissionais variados. A princípio, o número de entrevistas com usuários foi determinado buscando-se respeitar o critério da proporcionalidade em relação aos outros entrevistados, sendo o número final atingido por uma certa repetitividade das respostas obtidas, indicando a saturação dos temas. O roteiro de entrevista contou com cerca de oito a dez questões orientadoras, dependendo se dirigida para profissionais ou usuários. As questões para os usuários abordaram temas como: o conhecimento a respeito da homeopatia e diferenças da medicina alopática, motivo de encaminhamento ou procura pelo serviço, acesso e atendimento prestado, características da relação médico-paciente, resultados obtidos com o tratamento. Para os trabalhadores de saúde, os temas foram: as diferenças entre o atendimento homeopático e o da biomedicina, atenção prestada ao usuário, acolhimento e vínculo, efetividade do tratamento, e outras características do processo de trabalho. As entrevistas foram realizadas num único dia dentro de um período de dois meses.

O tratamento dos dados foi realizado por meio da análise de conteúdo do tipo análise temática proposta por Bardin (2002) e Minayo (2004). Como estratégia geral de análise foram observadas as proposições teóricas que embasaram esta investigação, operacionalizada por meio da escolha de três categorias de referência: acolhimento, vínculo e cuidado, entendendo-as como dimensões do conceito de integralidade.

Com base nessas três categorias, foi estudada a promoção da integralidade analisando-se a organização do serviço, os processos de trabalho e, especialmente, a prática médica homeopática. Este estudo cumpriu todos os preceitos éticos e legais referentes à pesquisa envolvendo seres humanos, conforme parecer n 065/2004 do Comitê de Ética em Pesquisa da Unisinos.

\section{Resultados e discussão}

O Centro de Saúde Modelo - CS Modelo, antigo Centro de Saúde 2, é uma unidade pertencente à Secretaria Municipal de Saúde de Porto Alegre, localizada na região central da cidade, de fácil acesso e próxima a dois importantes hospitais: o pronto socorro municipal, conhecido como HPS (Hospital de Pronto Socorro), e o Hospital de Clínicas da UFRGS. Essa unidade é constituída por um Ambulatório Básico, que presta atendimento em clínica geral, pediatria, ginecologia, odontologia e enfermagem. Faz 
parte também dessa unidade o Ambulatório de Especialidades, que presta atendimento em homeopatia, acupuntura, cardiologia, saúde mental (psicologia, psiquiatria e neurologia) e o SAOPE (Serviço de Atendimento Odontológico para Pacientes Especiais). O CS Modelo conta ainda com os serviços de tisiologia, farmácia homeopática, farmácia de medicamentos básicos e controlados, e sedia uma equipe do Programa de Saúde da Família.

Atualmente, o Serviço de Atendimento Homeopático do CS Modelo conta com duas médicas, uma com carga horária formal de vinte horas semanais, e a outra, com quarenta horas. No que se refere ao agendamento de consultas, a primeira é marcada por meio da Central de Marcação de Porto Alegre, mediante documento de referência e contra-referência. A reconsulta é marcada diretamente no CS de acordo com a disponibilidade da agenda de cada médica, em dia preestabelecido. As consultas têm um tempo médio de quinze minutos de duração, incluindo primeiras consultas e retornos, e o número médio de atendimentos mensais é de cerca de trezentos.

\section{Sobre a compreensão de homeopatia}

Para as médicas que atuam no serviço, existe uma diferença importante de paradigma entre a homeopatia e a medicina alopática, a partir do momento em que a primeira considera a existência de uma força vital que fundamenta sua terapêutica, possui uma abordagem diferenciada sobre a doença e a cura, e valoriza sintomas que não são considerados pela alopatia. Na prática homeopática existem duas categorias de sintomas que devem ser observadas: a que trata a natureza interior e a que se refere ao quadro nosológico. O médico homeopata deve investigar as condições de vida, relacionamentos sociais, hábitos alimentares e qual a natureza e peculiaridade das queixas relatadas pelo usuário, de forma a alcançar aquilo que é exclusivo (Lacerda, 2003; Luz, 1993).

A homeopatia é uma especialidade médica, não devendo ser referida como uma "prática alternativa" dentro do Sistema Único de Saúde; este é o posicionamento das médicas. É uma opção terapêutica, mas que pode, em certas condições de saúde, ser utilizada de forma complementar à alopatia. Esta referência foi feita, sobretudo, em relação às doenças crônicas e lesionais graves.

Os outros profissionais de saúde, na sua grande maioria, consideram a homeopatia uma terapêutica "alternativa", no sentido de que trata as pessoas de uma maneira diferente, associando a mesma a ervas naturais e florais. Os usuários entrevistados se referiram à homeopatia como um medicamento natural, mais saudável, sem efeitos colaterais.

Na maioria das falas é mencionado o fato de a homeopatia ser um tratamento mais demorado, porém com resultados melhores para a saúde, pois trata a "raiz" do problema que causou a doença. Esta colocação corrobora a fundamentação desta racionalidade médica, entendida como

todo o construto lógica e empiricamente estruturado das dimensões morfologia, dinâmica vital, doutrina médica, sistema de diagnose e sistema de intervenção terapêutica, tendendo a se constituir ou pretendendo constituir-se em sistema de proposições 'verdadeiras' e de intervenções eficazes face ao adoecimento humano. (Luz, 1996b, p.6)

Curar a doença, entendida como o desequilíbrio da energia vital, significa curar o sujeito, e não apenas acabar com os sintomas nosológicos; ao se curar o sujeito, por conseqüência, cura-se a patologia (Hahnemann, 2001; Kent, 1954).

(Entrevistado 8): É um remédio bem natural, que sei lá, ajuda bem mais que outros remédios que não fazem muito efeito, tipo antibiótico, que antes eu tomava e adiantava só na hora. $A$ homeopatia é um trabalho demorado, mas que adianta bem mais e é bem melhor pra saúde.

(Entrevistado 9): Ela trata a raiz, o que baixou a imunidade para causar aquela doença. Então ela trata o emocional para tratar a imunidade, né. 
O gestor do CS, embora reconheça a homeopatia como uma "nova opção" dentro da medicina, fato indiscutível, afirma que a especialidade apresenta algumas limitações terapêuticas, pois, em sua opinião, não dá conta de todas as doenças. Também não é prioritária para os gestores do SUS, que preferem investir na contratação de médicos para outras especialidades consideradas mais necessárias e resolutivas.

\section{Processos de trabalho e a integralidade em saúde}

Para Merhy et al. (1997), o cuidado integral em saúde ocorreria a partir da combinação das tecnologias duras, máquinas, normas, estruturas organizacionais; leve-duras, saberes estruturados, normas e rotinas; leves, vínculo, autonomização, acolhimento e gestão como uma forma de governar processos de trabalho. Quando solicitamos que os entrevistados nos falassem sobre sua compreensão de integralidade ou de um atendimento integral, várias questões referentes às categorias de estudo foram emergindo espontaneamente, tanto se referindo à estrutura do serviço, organização e rotinas de trabalho, como a aspectos mais ligados à subjetividade.

Em relação à organização do serviço, o atendimento integral foi reconhecido pelos entrevistados quando o profissional tem a possibilidade de: viabilizar o acesso do usuário ao serviço e às ações de saúde; encaminhar o usuário para avaliações especializadas; solicitar exames simples e complexos, quando se fizer necessário; e ter o retorno em tempo hábil.

O atendimento integral, abordado sob o aspecto da terapêutica, foi considerado como aquele alicerçado na escuta, na valorização dos sintomas físicos e mentais e, também, de questões mais gerais que acompanham ou são as próprias desencadeantes dos problemas de saúde da pessoa.

(Entrevistado 2): A integralidade é isso, tanto o transtorno físico como o que acompanha esse transtorno físico, que pode vir junto ou até ser o desencadeante numa situação.

(Entrevistado 3): É um sistema terapêutico que visa atender um grande número de pessoas e na sua totalidade. Aquele cujos sintomas físicos, como o mental estão em desequilíbrio, daí o medicamento homeopático vai equilibrar essa energia, que tá em desequilíbrio, pra chegar a uma cura e a uma qualidade de vida melhor também.

O entrevistado 3, responsável pela farmácia homeopática do serviço em estudo desde a sua implantação, demonstrou, na sua fala, reconhecer a homeopatia como sistema terapêutico que busca atender as necessidades de saúde de forma abrangente e universal. Esta característica da homeopatia, na visão do profissional, encontra-se em consonância com um dos princípios norteadores do SUS, a universalidade, previsto na Constituição Federal de 1988, e que preconiza que o Sistema de Saúde deve atender a toda população, sem distinções ou restrições, oferecendo toda a atenção necessária, sem qualquer custo (Brasil, 2005). A respeito do conceito de totalidade, a homeopatia, bem como outras medicinas alternativas ou complementares, tem, como seu paradigma epistemológico e de prática terapêutica, a vida, a saúde e o equilíbrio. A centralidade dessas categorias está presente nas dimensões da terapêutica, da diagnose, da doutrina médica, da dinâmica vital e da própria morfologia humana. É uma racionalidade médica que adota o vitalismo na abordagem dos processos de adoecimento e cura dos sujeitos, estabelecendo ou reestabelecendo para a medicina o papel de promotora e recuperadora da saúde e de auxiliar de vida, acompanhando o discurso atual da promoção de saúde, associado à qualidade de vida, saúde, solidariedade, eqüidade, democracia, cidadania, desenvolvimento, entre outros (Luz, 2005; Buss, 2003).

As dificuldades em relação à acessibilidade, especialmente em relação à marcação de consultas, sobretudo da primeira, prevaleceram como aspecto negativo do serviço. Segundo Acurcio e Guimarães (1996), acessibilidade seria a capacidade de obtenção de cuidados em saúde, quando necessário, de modo fácil e conveniente. O conceito de acesso está relacionado a três subcategorias denominadas: acesso geográfico, acesso econômico e acesso funcional (Ramos, Lima, 2003; Unglert, 1994). O acesso geográfico foi caracterizado por forma e tempo de deslocamento e distância entre a residência do usuário e o serviço de saúde. O acesso econômico, pelas facilidades e dificuldades que o usuário 
encontra para obter o atendimento, considerando que a totalidade dos serviços de saúde não está disponível a todos os cidadãos. O acesso funcional envolveria a entrada propriamente dita aos serviços de que o usuário necessita, incluindo-se os tipos de serviços oferecidos, os horários previstos e a qualidade do atendimento. No caso do CS Modelo, a marcação da primeira consulta está vinculada à Central de Marcação de Porto Alegre, e as consultas seguintes são remarcadas na unidade em dia do mês previamente estabelecido, gerando filas e longo tempo de espera.

A disponibilização de medicamentos de forma gratuita nas unidades do SUS foi considerada, pelos usuários entrevistados, componente importante de um atendimento integral à saúde. Em sua fala, a falta de medicamentos nas unidades é um aspecto negativo dos serviços públicos e foi referida como ponto positivo no serviço de atendimento homeopático - faz parte da unidade uma farmácia de manipulação que disponibiliza os medicamentos gratuitamente.

Um dos aspectos abordados pelos trabalhadores, quando indagados sobre a integralidade no atendimento, referiu-se às próprias condições de trabalho consideradas ruins. Deram, como exemplo, os prontuários do serviço que se encontram dispostos em arquivos pesados, dificultando o manuseio e ocasionando tendinites e outras doenças musculoesqueléticas e o afastamento do trabalho.

Já no entendimento do gestor da unidade, os hospitais, por suas características e modo de funcionamento, são mais apropriados e aproximam-se mais do modelo de integralidade da atenção em saúde, pois faz parte da rotina hospitalar o trabalho interdisciplinar de equipe multiprofissional que atua em torno de um caso clínico. Para ele, os médicos em geral possuem uma tendência a trabalharem isolados, sem comunicação entre si e os demais profissionais e setores, costumando resistir à unificação dos prontuários clínicos e troca de saberes.

(Entrevistado 10): O que é integralidade no atendimento? É uma pergunta difícil, porque nós médicos temos uma tendência a trabalharmos meio isolados; essa integralidade, pelo menos no posto de saúde, eu vejo ela muito difícil, eu até entendo ela no hospital.

Observa-se que o gestor aponta uma característica inerente à prática médica em ambientes não hospitalares, que seria a questão do isolamento e da dificuldade em estabelecer relações de troca, colocando naturalmente em foco a necessidade de discussão da graduação médica e de se repensar os cursos de formação e capacitação destes profissionais. Por outro lado, parece haver certa idealização do espaço hospitalar, ficando o tema da integralidade muitas vezes restrito à concepção de trabalho interdisciplinar e multiprofissional em torno da doença, desconsiderando a possibilidade desta dinâmica de trabalho multiprofissional e interdisciplinar em outros ambientes de atenção à saúde e, também, a importância de outras formas de cuidado e de reestruturação de processos de trabalho que possam contribuir para a integralidade da atenção, tais como: o acolhimento, a criação de redes matriciais, a implementação de formas de gestão participativa e outras estratégias de organização das práticas e do próprio sistema de saúde (Pinheiro, Luz, 2003; Campos, 1997; Mehry, 1997).

Pinheiro e Luz (2003) afirmam que as instituições de saúde assumem papel estratégico na absorção dos conhecimentos de novas formas de agir e produzir integralidade em saúde, na medida em que reúnem, no mesmo espaço, médicos, usuários e gestores com perspectivas diferentes e interesses distintos. O que se percebe no CS Modelo é que o mesmo reúne práticas de saúde com saberes diferenciados, mas que funcionam de maneira isolada, não interagindo entre si. Do mesmo modo, na unidade, não existem espaços coletivos que propiciem a interlocução entre os atores no cotidiano destas práticas. Esta questão foi apontada por uma das médicas, quando se referiu ao fato de, neste momento, não haver tempo e espaço nem mesmo para as discussões clínicas em homeopatia.

\section{O acolhimento no CS Modelo}

A temática do acolhimento nos serviços de saúde adquire importância crescente no campo médico-sanitário e, de acordo com Teixeira (2003, p.98), "vem requalificando a discussão a respeito do problema do acesso e da recepção dos usuários nos serviços de saúde", objetivando a qualificação e humanização das relações entre os serviços de saúde/trabalhadores com os usuários. O acolhimento, 
enquanto diretriz operacional, pressupõe a atenção a todas as pessoas que procuram os serviços de saúde e a reorganização do processo de trabalho, deslocando o eixo central do médico para uma equipe multiprofissional que se encarrega da escuta do usuário, comprometendo-se a resolver seu problema (Franco, Magalhães, 2003).

No CS Modelo não existe uma equipe de acolhimento, mas este tema já foi abordado com os trabalhadores de saúde na gestão anterior, durante reuniões específicas sobre o seu processo de implantação na unidade. De acordo com os profissionais, na prática, este modo de organizar o serviço não se efetivou até o momento.

(Entrevistado 4): O nosso Posto não está assim envolvido no sistema de acolhimento, o Posto todo não está envolvido.

No entanto, quando abordado especificamente sob o enfoque da consulta médica, do atendimento dispensado pelas médicas homeopatas que atuam no serviço, o "acolhimento" na unidade foi considerado muito bom por todos os entrevistados. $O$ atendimento destes profissionais foi referido como sendo pautado pelo diálogo, afeto e atenção, corroborando Teixeira (2003), que se refere à necessidade de o acolhimento ter também um caráter de acolhimento moral do usuário do serviço e de suas demandas, que podem envolver um sofrimento importante. De acordo com o mesmo autor, o diálogo, neste caso, teria por objetivo buscar maior conhecimento das necessidades de que o usuário se faz portador e dos modos de satisfazê-las.

O gestor atual da unidade referiu que o termo acolhimento foi muito utilizado pela gestão anterior, mas que a implantação desse novo modo de organizar o serviço deixa muito a desejar na unidade. Segundo o entrevistado (gestor atual), para se ter um bom acolhimento, o CS Modelo teria de contar com local adequado e com profissionais capacitados para identificar e hierarquizar as demandas dos usuários, não as supervalorizando desnecessariamente, a fim de não ocasionar um aumento das mesmas e a dificuldade em atendê-las.

Ao se tratar do acolhimento ao usuário, a questão da acessibilidade voltou a ser apontada pelos entrevistados como um tema de extrema relevância. Voltaram à tona questões envolvendo o acesso geográfico e funcional. A centralização do atendimento homeopático pelo SUS no CS Modelo, o número insuficiente de médicos atendendo no serviço, as dificuldades já mencionadas para o agendamento de consultas, a sobrecarga ocasionada pelo atendimento usual de intercorrências e a demanda reprimida foram apontados como os principais motivos para que o serviço não consiga oferecer um acolhimento adequado, sobretudo, sob a perspectiva do acesso, recepção no serviço e solução das demandas. Observou-se, no entanto, que alguns dos problemas citados estavam relacionados também à existência de vínculos empregatícios diferenciados dos profissionais do serviço, repercutindo, inclusive, no cumprimento de carga horária.

Percebemos, por meio de observação direta que, em termos de instalações físicas, o serviço realmente não conta com local adequado para recepção e acolhimento dos usuários: os mesmos aguardam por suas consultas em bancos de madeira colocados no final de um corredor em frente à porta do consultório. No entanto, sabe-se que o acolhimento é um dispositivo que vai muito além da simples recepção do usuário e local adequado para atendimento, devendo ser considerada toda a situação de atenção a partir de sua entrada no sistema (Franco, 2003; Leite, Maia, Sena, 1999).

Chamou a atenção também que, para alguns dos entrevistados, foi estabelecida uma relação direta entre "ser bem atendido" e uma postura passiva por parte do usuário do sistema. O gestor considerou que o atendimento na unidade, dentro do possível, é bom, e que os usuários em geral são tranqüilos e muito passivos, aceitando bem as dificuldades, reivindicando muito pouco os seus direitos, questão esta que aparece também na fala de uma das médicas e de uma usuária. Segundo Campos (1997, p.181), "a relação profissional/cliente é concebida como intercâmbio entre um sujeito potente - geralmente o médico - e um objeto suposto de ser dócil, ativo apenas quando presta informações necessárias ao diagnóstico". O mesmo autor acrescenta que a própria denominação 'paciente', utilizada usualmente quando se faz referência ao doente, já revela, conceitualmente, uma situação em que o mesmo teria de suportar os sofrimentos sem queixa. 
(Entrevistado 9): Eu vim sujeitada a ganhar um atendimento gratuito, gratuito, né, entre aspas porque alguém paga por esse atendimento, os funcionários não estão aqui sem receber, né?! Tu tem que te sujeitar a fazer sem questionar.

Sobre o sistema de referência e contra-referência e a resolução das demandas, segundo o gestor, há resolutividade na medida do possível, porque a unidade depende demais do sistema secundário e terciário no que se refere a consultas especializadas e à realização de exames de média e alta complexidade.

\section{Vínculo e confiança: a relação médico-usuário}

A relação médico-usuário é um dos determinantes da resolução dos problemas de saúde, e a grande parte da efetividade médica resulta da satisfação das pessoas durante o processo de tratamento. Esta satisfação não se limita ao aspecto técnico-científico da medicina, mas inclui também a qualidade do vínculo, comunicação interpessoal e o modo como se estabelecem essas relações (Luz, 1997).

Ao abordarem este tema, as médicas iniciaram traçando o perfil dos usuários na tentativa de explicar o porquê da vinculação dos mesmos ao serviço. Na maioria são mulheres de meia-idade, um grande número de idosos e crianças, que geralmente pertencem a uma "classe média falida". Muitos são aposentados, professores, artistas, que residem no entorno da unidade, usualmente portadores de doenças crônicas, alguns extremamente sofridos, com muitas perdas e problemas emocionais, por estes motivos se vinculam com muita intensidade e são bastante assíduos. Foi referido que os idosos, em especial, estabelecem um vínculo muito bom com o serviço e que, geralmente, são pessoas amigas, carinhosas, pacientes e gratas aos profissionais.

De acordo com as entrevistas, o vínculo mais forte entre médicos e usuários se inicia a partir do momento em que os resultados terapêuticos positivos começam a aparecer, quando, então, o usuário passa a ter mais confiança e a compreender melhor a racionalidade da prática homeopática. A homeopatia está baseada na valorização do indivíduo enquanto totalidade, e não somente em sintomas e doenças específicas, centrando-se na terapêutica, e não na diagnose, e utilizando a narrativa como instrumento fundamental da consulta. Isto torna a relação médico-usuário valorizada como recurso terapêutico que ajuda a compreender a singularidade do sujeito doente e curar ou aliviar o sofrimento (Lacerda, 2003).

De acordo com Luz (1997), a relação médico-paciente pode ser considerada um dos determinantes da resolubilidade dos problemas de saúde, grande parte do sucesso da prática médica resulta da satisfação do paciente em relação ao tratamento.

Foi colocado pelas médicas que o atendimento homeopático é diferenciado porque nele a escuta é muito valorizada, mesmo que, por meio dela, nem sempre seja possível resolver todos os problemas de saúde do usuário. Consideram que muitos dos insucessos de alguns tratamentos estão diretamente relacionados à falta de tempo que o médico tem para ouvir seus pacientes, resultando num tratamento inadequado. Sabe-se que a relação médico-usuário é permeada por tensões e conflitos que envolvem relações de poder e processos de subjetivação, independentemente da racionalidade em questão. Martins (2003) argumenta que podemos identificar inúmeros médicos alopatas que não se deixam seduzir pela rigidez do conhecimento canônico e desenvolvem uma escuta clínica e humana semelhante; do mesmo modo que é possível identificar terapeutas alternativos que, por trás do discurso renovador, demonstram ser utilitaristas e egoístas; chamando a atenção para o fato de que o tipo de relação estabelecida independe da racionalidade médica em questão, estando esta sustentada num atendimento humanizado calcado no tripé encontros-afetos-conversas (Teixeira, 2005). Entretanto, não há como desconsiderar que a homeopatia, ao valorizar a escuta como procedimento essencial a sua prática, favorece o sucesso da relação terapêutica e, conseqüentemente, influi positivamente no tratamento.

Para os outros trabalhadores que atuam no serviço homeopático, o vínculo que se estabelece é muito forte; os usuários se apegam às médicas, chegam ao serviço e as procuram pelo nome, não aceitando serem atendidos por outro profissional. A satisfação do usuário parece estar diretamente relacionada à qualidade do vínculo estabelecido. Na opinião da farmacêutica, este fato está associado à anamnese homeopática, que é bem mais detalhada, para possibilitar ao médico encontrar o 
medicamento do paciente. Na homeopatia, a individualização é muito relevante, por este motivo, Hahnemann (2001) ressaltou a necessidade de o médico observar e escutar os usuários sem julgamento ou interpretações, valorizando os sintomas subjetivos e objetivos narrados pelos mesmos. Para a farmacêutica, na medida em que vai se estabelecendo uma relação maior de vínculo e confiança, os usuários vão relatando, cada vez mais, seus problemas e sofrimentos.

(Entrevistado 7): É uma deusa, é uma deusa, a doutora A. é fora de série, filha. Ela tem tanto carinho com a gente velha, a gente chega, ela abraça a gente como seja da família, quando sai ela abraça a gente, ela diz "volta de novo".

$\mathrm{Na}$ fala dos usuários, as médicas são tidas como pessoas boas, alegres, carinhosas, que sabem ouvir e entender o paciente. Acrescentam ainda que conversam sobre tudo com elas, não somente sobre os problemas de saúde que os levaram ao serviço. Comparando o atendimento homeopático e o alopático, referiram-se ao tempo diferenciado da consulta, a impessoalidade dos médicos alopatas que trabalham no SUS e ao fato de eles se aterem somente às doenças.

Por outro lado, foi dito que o médico alopata examina e solicita mais exames complementares que o homeopata, questões identificadas como parâmetros de qualidade pelos usuários entrevistados. $\mathrm{Na}$ biomedicina, quando se pretende diagnosticar uma doença e tratá-la, são priorizados os sintomas objetivos e as alterações corporais diagnosticadas por meio de exames complementares muitas vezes sofisticados, em detrimento da abordagem de aspectos subjetivos do adoecer, que envolvem as queixas emocionais, os sentimentos e a singularidade do processo saúde-doença, não validados por alguns profissionais de saúde (Lacerda, 2003). Ao se objetivar a doença e nomeá-la, não se leva em consideração que a doença do médico não corresponde necessariamente à doença do paciente (Canguilhem, 2002), podendo gerar um desencontro entre os significados pessoais do adoecimento e a percepção médica e os resultados da ação terapêutica. Além disso, os recursos tecnológicos da medicina e o poder da mídia na divulgação e ideologização do público em geral sobre os avanços nesse campo e o consumo dessas novas tecnologias acabam repercutindo no imaginário e na percepção das necessidades de saúde por parte da população em geral (Castiel, 2007, 2003, 1999).

Para o gestor da unidade, a questão da relação médico-usuário ser ou não pautada pelo vínculo e confiança está diretamente ligada ao estilo do profissional, e não à racionalidade médica em questão. Importa a atenção que o médico dispensa durante a consulta e "esta coisa mágica" que faz com que o usuário confie num sujeito que nunca viu anteriormente. Coloca que uma boa relação médico-paciente não é muito fácil, sobretudo num sistema de saúde onde o profissional tem uma série de dificuldades para dar um bom atendimento, é desvalorizado e visto pelo usuário como sendo o próprio sistema.

\section{Cuidado, cura e alívio do sofrimento}

O cuidado seria mais que um momento de atenção, de zelo e de desvelo; representaria uma atitude interativa de ocupação, preocupação, de responsabilização e envolvimento afetivo para com o próximo. O cuidado seria apreendido como uma ação integral voltada para a compreensão da saúde como um direito de ser; seria a atenção ao sofrimento, freqüentemente fruto de fragilidade social, com tratamento digno, acolhedor e respeitoso (Luz, 2004; Boff, 2000).

Quando abordamos o tema 'cuidado' optamos por fazê-lo sob os seguintes enfoques: cura ou alívio do sofrimento, atendimento às necessidades de saúde, e o fato de o usuário ser ou não assumido como um todo pelo serviço. $O$ entendimento dos entrevistados sobre o tema foi muito associado à questão da resolubilidade, especialmente sob a perspectiva da cura e alívio de sintomas, observando-se uma hierarquização dos conceitos por parte dos entrevistados.

Não existiu consenso a respeito de a homeopatia curar ou somente aliviar o sofrimento. Uma profissional disse que nunca ouviu nenhum usuário referir-se ao fato de ter sido realmente curado pela homeopatia, mas concorda que alivia muito o sofrimento das pessoas. Os demais consideraram a existência de casos nos quais a homeopatia pode realmente curar e de outros em que somente traz o alívio - para as médicas, isto vai depender do problema de saúde. 
A respeito do processo de cura na homeopatia, Constantine Hering, médico homeopata, discípulo de Hahnemann, que sistematizou as Leis de Cura homeopáticas, conhecidas por "Leis de Hering", a melhora dos sintomas ocorre de cima para baixo e desaparecem na ordem inversa de seu aparecimento; a melhora da enfermidade ocorre de dentro para fora, do mental para o físico, sendo que o alívio aparece primeiramente nos órgãos mais importantes, e os sintomas da pele e das mucosas são os últimos a desaparecer (Hering apud Eizayaga, 1981). Nos dias atuais, sabe-se que grande parte da demanda por atendimento médico envolve queixas relacionadas a sofrimentos físicos e psíquicos genéricos, inespecíficos, não contemplados e muito menos equacionados pelo arcabouço anátomopatológico e clínico constituído pelo modelo biomédico, trazendo a categoria "alivio" à centralidade das práticas em saúde.

As médicas também relacionaram esses resultados ao pouco tempo que têm tido para fazerem o estudo aprofundado de cada paciente e para discussões clínicas - situação decorrente, segundo elas, do excesso de demanda e do número insuficiente de profissionais atuando no serviço neste momento. De acordo com Lacerda e Valla (2004), para que o profissional consiga identificar o sofrimento e ajudar os sujeitos, é necessário escutá-los para saber o que sentem e temem, objetivando validar o que é relatado pelos mesmos.

(Entrevistado 2): Ele pode se curar e às vezes só traz alivio, são as duas funções também. Precisa curar, se não der pra curar, alivia.

(Entrevistado 7): Cura, filha. Eu estava muito doente esses tempos e ela me receitou arnica e umas outras coisas e foi uma beleza, né.

Os profissionais de saúde acreditam que, no serviço, o usuário é assumido como um todo, mas relacionaram isto às características terapêuticas e à maneira como a medicação homeopática age no indivíduo. Já os usuários relataram que as médicas são afetuosas e têm uma preocupação com o bemestar do paciente, e se sentem inteiramente assumidos pelo serviço, tal como afirma Machado et al. (2004, p.69) quando diz que "a procura pela homeopatia está associada à busca por uma 'humanização' do atendimento (associada pelos pacientes a termos como confraternização, carinho e amor)".

Para o gestor, os médicos, em geral, não curam, apenas aliviam o sofrimento de seus pacientes. Afirmou que hoje, na medicina, a maioria das doenças não tem cura, citando como exemplos: a hipertensão, o diabetes e as doenças reumatológicas.

Com base na observação, na análise de documentos e nas entrevistas, percebemos que há uma série de problemas que têm prejudicado o bom funcionamento do serviço, que vão desde a forma de agendamento e acolhimento dos usuários, a presença de diferentes vínculos empregatícios, passando por dificuldades de aquisição de matéria-prima para a farmácia homeopática até falhas nos sistemas de referência e contra-referência.

\section{Considerações finais}

A organização do Sistema Único de Saúde brasileiro ainda tem como grande desafio o atendimento adequado às necessidades da população. A crítica ao modelo hegemônico de atenção baseado na biomedicina tem produzido análises pautadas em questões estruturais, de ordem política, social e econômica (Campos, 1997; Mendes et al., 1994; Merhy, 1992). O aumento da demanda de atenção médica em decorrência de problemas de saúde abrangentes, que incluem aspectos psicossociais, do desequilíbrio da demanda-oferta dos serviços públicos de saúde e da baixa resolubilidade do modelo biomédico, faz com que seja necessário redefinir práticas de atenção, superando a visão cartesiana e reducionista e reorganizando os serviços.

Valla (2005) enfatiza que, nos dias atuais, mesmo com uma rede de saúde pública extensa, não tem sido possível atender a uma queixa usual das pessoas, denominada "sofrimento difuso" - dores de cabeça, dores no corpo, medo, ansiedade - sintomas para cujo tratamento o sistema não dispõe nem de 
tempo nem de recursos, restando à medicina tradicional medicalizar o problema. A oferta de atendimento homeopático pelo SUS traria às classes populares a oportunidade de uma atenção diferenciada, mais adequada na abordagem dos sofrimentos contemporâneos, e que concorre com os princípios de humanização e de resolubilidade dos serviços.

Observou-se que, no caso analisado, a promoção da integralidade da atenção à saúde tem sido restrita a alguns de seus aspectos, como o vínculo e o cuidado diretamente associados à relação médico-usuário. No entanto, o processo de trabalho foi pouco problematizado; pode-se dizer que o acolhimento no serviço inexiste e sua implantação não parece prioridade. Ao longo do tempo, ocorreu perda de profissionais e de espaço físico dentro da unidade de saúde, havendo o aumento da demanda reprimida. A acessibilidade foi uma das questões mais identificadas como problema, e a centralização deste tipo de atendimento em um único serviço na cidade é um dos fatores que têm dificultado o acesso dos usuários. A própria gestão do serviço demonstrou clara falta de adesão, comprometimento e interesse em investir num modelo não biomédico, contrariando a Política Nacional de Práticas Integrativas e Complementares no SUS (portaria MS n 971/2006).

Embora a homeopatia seja uma racionalidade médica coerente e fortalecedora dos princípios do SUS, é preciso que ela seja reconhecida, valorizada e disponibilizada como opção terapêutica a toda população, contribuindo na promoção da integralidade em saúde.

\section{Colaboradores}

Os autores Carolina Santanna e Élida Hennington participaram, igualmente, da elaboração do artigo, de sua discussão e redação, e da revisão do texto. Roque Junges participou da revisão bibliográfica, de discussões e revisão do texto. Carolina Santanna desenvolveu as atividades de campo da pesquisa.

\section{Referências}

ACURCIO, E.A.; GUIMARÃES, M.D.C. Acessibilidade de indivíduos infectados pelo HIV aos serviços de saúde: uma revisão de literatura. Cad. Saúde Pública, v.12, suppl., p.233-42, 1996.

BARDIN, L. Análise de conteúdo. Lisboa: Edições 70, 2002.

BOFF, L. Saber cuidar: ética do humano - compaixão pela terra. Petrópolis: Vozes, 2000.

BRASIL. Ministério da Saúde. Conselho Nacional de Secretários Municipais de Saúde. O SUS de A a Z: garantindo saúde nos municípios. Brasília: Ministério da Saúde, 2005.

BUSS, P.M. Uma introdução ao conceito de promoção da saúde. In: CZERESNIA, D. et al. (Orgs.). Promoção da saúde: conceitos, reflexões, tendências. Rio de Janeiro: Fiocruz, 2003. p.15-38.

CAMPOS, G.W.S. Reforma da reforma: repensando a saúde. São Paulo: Hucitec, 1997.

CANGUILHEM, G. O normal e o patológico. Rio de Janeiro: Forense Universitária, 2002. 
CARVALHO, A. Da saúde pública às políticas saudáveis: saúde e cidadania na pósmodernidade. Cienc. Saúde Coletiva, v.1, n.1, p.104-21, 1996.

CASTIEL, L.D. A saúde persecutória: os limites da responsabilidade. Rio de Janeiro: Fiocruz, 2007.

. Dédalo e os Dédalos: identidade cultural, subjetividade e os riscos à saúde. In: CZERESNIA, D. et al. (Orgs.). Promoção da saúde: conceitos, reflexões, tendências. Rio de Janeiro: Fiocruz, 2003. p.79-95.

A medida do possível... saúde, risco e tecnobiociências. Rio de Janeiro: Contra Capa/Fiocruz, 1999.

COMISSÃO DE SAÚDE PÚBLICA. ASSOCIAÇÃO MÉDICA HOMEOPÁTICA BRASILEIRA. A homeopatia no Sistema Único de Saúde: histórico e situação atual. Disponível em: <http://www.homeopathicum.com.br/ler>. Acesso em: 19 ago. 2004.

EIZAYAGA, F.X. Tratado de Medicina Homeopática. Buenos Aires: Ediciones Merecel, 1981.

FRANCO, T.B.; MAGALHÃES, J.R.H.M. Integralidade na assistência à saúde: a organização das linhas do cuidado. In: MERHY, E.E. et al. (Orgs.). O trabalho em saúde: olhando e experienciando o SUS no cotidiano. São Paulo: Hucitec, p.125-133, 2003.

GUEDES, C.R.; NOGUEIRA, M.I.; CAMARGO JR., K.R. A subjetividade como anomalia: contribuições epistemológicas para a crítica do modelo biomédico. Cienc. Saúde Coletiva, v.11, n.4, p.1093-103, 2006. Disponível em: <http://www.scielo.br/ scielo. php? script $=$ sci arttext $\&$ pid $=s 1413-81232006000400030 \& \operatorname{lng}=$ pt $\&$ nrm $=i s o>$. Acesso em: 13 set. 2007.

HAHNEMANN, S. Organon da arte de curar. São Paulo: Robe Editorial, 2001. KENT, J.T. Lições de filosofia homeopática. Curitiba: Nova Época, 1954.

LACERDA, A.; VALLA, V.V. As práticas terapêuticas de cuidado integral à saúde como proposta para aliviar o sofrimento. In: PINHEIRO, R.; MATTOS, R.A. (Orgs.). Cuidado: as fronteiras da integralidade. Rio de Janeiro: Hucitec/Abrasco, 2004. p. 91-102.

Homeopatia e apoio social: repensando as práticas de integralidade na atenção e no cuidado à saúde. In: PINHEIRO, R.; MATTOS, R.A. (Orgs.). Construção da integralidade: cotidiano, saberes e práticas em saúde. Rio de Janeiro: UERJ/IMS/ Abrasco, 2003. p.169-96.

LEITE, J.C.A.; MAIA, C.C.A.; SENA, R.R. Acolhimento: perspectiva de reorganização da assistência de enfermagem. Rev. Bras. Enferm., v.52, n.2, p.161-8, 1999.

LUZ, H.S. Racionalidades médicas: a medicina homeopática. Rio de Janeiro: IMS/UERJ, 1993. (Série Estudos em Saúde Coletiva, 64).

LUZ, M.T. Cultura contemporânea e medicinas alternativas: novos paradigmas em saúde no fim do século XX. Physis, v.15, suppl., p.145-76, 2005.

. Fragilidade social e busca de cuidado na sociedade civil de hoje. In: PINHEIRO, R.; MATTOS, R.A. (Orgs.). Cuidado: as fronteiras da integralidade. Rio de Janeiro: Hucitec/Abrasco, 2004. p.9-20.

Cultura contemporânea e medicinas alternativas: novos paradigmas em saúde no fim do século XX. Physis, v.7, n.1, p.13-45, 1997. 
LUZ, M.T. A arte de curar versus a ciência das doenças: história social da homeopatia no Brasil. São Paulo: Dynamis, 1996a.

V Seminário do Projeto Racionalidades Médicas. Rio de Janeiro: IMS, 1996b. (Série Estudos em Saúde Coletiva, 136).

Natural, racional, social: razão médica e racionalidade científica moderna. Rio de Janeiro: Campus, 1988.

MACHADO, F.R.S.; PINHEIRO, R.; GUIZARDI, F.L. As novas formas de cuidado integral nos espaços públicos de saúde. In: PINHEIRO, R.; MATTOS, R.A. (Orgs.). Cuidado: as fronteiras da integralidade. Rio de Janeiro: Hucitec/Abrasco, p.57-74, 2004.

MARTINS, P.H. Contra a desumanização da medicina: crítica sociológica das práticas médicas modernas. Rio de Janeiro: Vozes, 2003.

MATTOS, R.A. Integralidade e a formulação de políticas específicas de saúde. In: PINHEIRO, R.; MATTOS, R.A. (Orgs.). Construção da integralidade: cotidiano, saberes e práticas em saúde. Rio de Janeiro: UERJ/IMS/Abrasco, p.45-59, 2003

Os sentidos da integralidade: algumas reflexões acerca de valores que merecem ser defendidos. In: PINHEIRO, R.; MATTOS, R.A. (Orgs.). Os sentidos da integralidade na atenção e no cuidado à saúde. Rio de Janeiro: UERJ/IMS/Abrasco, p.39-64, 2001.

MENDES, E.V. et al. (Orgs.). Distrito Sanitário: o processo social de mudança das práticas sanitárias do Sistema Único de Saúde. São Paulo: Hucitec, 1994.

MERHY, E.E. Em busca do tempo perdido: a micropolítica do trabalho vivo em saúde. In: MERHY, E. E.; ONOCKO, R. (Orgs.). Agir em saúde: um desafio para o público. São Paulo: Hucitec, 1997. p.71-112.

A saúde pública como política: um estudo dos formuladores de políticas. São Paulo: Hucitec, 1992.

MINAYO, M.C.S. O desafio do conhecimento: pesquisa qualitativa em saúde. São Paulo: Hucitec, 2004.

PINHEIRO, R.; LUZ, M.T. Práticas eficazes $x$ modelos ideais: ação e pensamento na construção da integralidade. In: PINHEIRO, R.; MATTOS, R.A. (Orgs.). Construção da integralidade: cotidiano, saberes e práticas em saúde. Rio de Janeiro: UERJ/IMS/ Abrasco, p.07-34, 2003.

RAMOS, D.D.; LIMA, M.A.D.S. Acesso e acolhimento aos usuários em uma unidade de saúde de Porto Alegre, Rio Grande do Sul, Brasil. Cad. Saúde Pública, v.19, suppl.1, p. 27-34, 2003.

SANTANNA, C. A prática médica homeopática no Centro de Saúde Modelo e o princípio da integralidade: um estudo de caso. 2005. Dissertação (Mestrado em Saúde Coletiva) - Programa de Pós-Graduação em Saúde Coletiva, Universidade do Vale Rio dos Sinos, São Leopoldo. 2005.

TEIXEIRA, R.R. Humanização e atenção primária à saúde. Cienc. Saúde Coletiva, v.10, n.3, p.585-97, 2005. Disponível em: <http://www.scielo.br/scielo.php?script=sci_ arttext\&pid $=$ S1413-81232005000300016\&lng $=p t \& n r m=$ iso $>$. doi: $10.1590 /$ S1413-81232005000300016. Acesso em: 28 nov. 2007. 
TEIXEIRA, R.R. O acolhimento num serviço de saúde entendido como uma rede de conversações. In: PINHEIRO, R.; MATTOS, R.A. (Orgs.). Construção da integralidade: cotidiano, saberes e práticas em saúde. Rio de Janeiro: UERJ/IMS/Abrasco, 2003. p.89-111.

TRIVIÑOS, A.N.S. Introdução à pesquisa em ciências sociais: a pesquisa qualitativa em educação. São Paulo: Atlas, 1987.

UNGLERT, C.V.S. Territorialização em sistemas de saúde. In: MENDES, E.V. (Org.). Distrito Sanitário: o processo social de mudança das práticas sanitárias do Sistema Único de Saúde. São Paulo: Hucitec, 1994. p.221-35.

VALLA, V.V. Classes populares, apoio social e emoção: propondo um debate sobre religião e saúde no Brasil. In: MINAYO, M.C.; COIMBRA, C.E. (Orgs.). Críticas e atuantes: ciências sociais e humanas em saúde na América Latina. Rio de Janeiro: Fiocruz, 2005. p.77-89.

YIN, R.K. Estudo de caso: planejamento e métodos. Porto Alegre: Bookman, 2001.

SANTANNA, C.; HENNINGTON, E.A.; JUNGES, J.R. Práctica médica homeopática y la integralidad. Interface - Comunic., Saúde, Educ., v.12, n.25, p.233-46, abr./jun. 2008.

El Centro de Saúde Modelo ha sido la primera unidad del Sistema Unificado de Saúde brasileño que ha implantado el servicio de atendimiento homeopático en Rio Grande do Sul. Este estudio tuvo por objeto conocer la contribución de dicho atendimiento para el desarrollo del principio de la integralidad. Se trata de estudio de caso, utilizando como categorías norteadoras la acogida, el vínculo y el cuidado, siendo los datos producidos a partir de documentación, observación directa y entrevistas con usuarios y trabajadores. Los resultados indican que la homeopatía, al acoger y tratar a personas en su singularidad y totalidad, permite una atención diferenciada. Sin embrago la integralidad se ha restringido a algunos de sus aspectos como el vínculo y el cuidado directamente asociados a la relación médico-usuario. La dificultad de acceso ha sido el principal problema identificado. Coherente y fortalecedora de los principios del Sistema Unificado de Saúde, la homeopatía ha de ser valorada como opción terapéutica para que pueda efectivamente contribuir en la integralidad de la atención en salud.

Palabras clave: Integralidad. Homeopatía. Gestión en salud. Estudio de caso. 